\title{
Exploring the relationship between demographic factors, performance and fortitude in a group of diverse 1st-year medical students
}

\author{
S Hamid, BSocSc, BSocSc Hons, MA, PhD; V S Singaram, BMedSc, MMedSc, PhD \\ Clinical and Professional Practice, School of Clinical Medicine, College of Health Sciences, University of KwaZulu-Natal, Durban, South Africa
}

Corresponding author: S Hamid (shaista.saib@gmail.com)

Background. The majority of 1st-year students are ill-equipped for university life. This heightens stress levels, which are accentuated by a lack of resilience and impact negatively on academic performance and personal wellbeing.

Objectives. To explore, within the paradigm of positive psychology, the relationship between the self, family and support constructs of fortitude, and academic performance of 1st-year medical students.

Method. First-year medical students completed a fortitude questionnaire and their academic performances in two academic modules were collated. Mann-Whitney and Kruskal-Wallis tests were employed for statistical analysis of the variables. Pearson correlation coefficients were calculated to assess the relationship between academic performance and fortitude subscales, as well as the fortitude composite score.

Results. The student population was multicultural, multilingual and had different educational and residential backgrounds. The fortitude instrument was found to be reliable and correlated significantly with student academic performance. Male students had significantly higher fortitude scores than female students. Students who had attended state/government schools had significantly lower fortitude than those who had attended private and ex-Model C schools. Students with prior degrees had higher fortitude than matriculants.

Conclusion. The significant, albeit moderate, positive correlation between fortitude and academic performance highlights the need for further exploration of wellbeing and holistic development of medical students. Support programmes are recommended to bridge the gap related to gender and educational background. Low and fair levels of fortitude indicate a need for corrective measures. These could include consulting relevant support networks such as student counsellors, mentors and academic development personnel.

Afr J Health Profession Educ 2016;8(1 Suppl 1):99-103. DOI:10.7196/AJHPE.2016.v8i1.748

The majority of 1st-year students are ill-equipped for university life and academia. This under-preparedness is accentuated by literacy issues, socioeconomic factors and lack of resilience. ${ }^{[1]}$ These issues heighten stress levels, which affect academic performance and personal wellbeing. ${ }^{[2]}$ Although psychological morbidity may be high among university students, it is often neglected in educational settings. Emotions are the primary forces driving motivation, and poor control and understanding of one's own or others' emotions may result in flawed social interactions. ${ }^{[3]}$ For health practitioners, this finding is crucial, as it may not only potentially compromise academic functioning and their personal wellbeing, but may also, in the long term, affect patient care. It has been reported that there is a paucity of research on the coping and adjustment of medical professionals, particularly in the South African (SA) context. ${ }^{[4]}$ This view is reiterated by O'Rourke et al. ${ }^{[5]}$ and Greysen et al. ${ }^{[6]}$ with regard to medical students. The former authors note that although medical students' distress is acknowledged, more research into causes and intervention strategies is needed. The latter asserts that the dramatic changes in sub-Saharan Africa over the past few decades necessitate a greater diversity of research into the perspectives and experiences of and within medical education. Barriers to student success that compound adjustment issues affect throughput and retention rates at SA universities, accounting to a large degree for high dropout rates. ${ }^{[7]}$ Despite these findings, it appears that tertiary institutions still place primary emphasis on intellectual/cognitive factors, ultimately overlooking the possibility of non-cognitive factors as significant role players in student success.

The study of positive psychology concerns itself with all aspects of positive living, and the fostering of inter- and intrapersonal resources for personal development and happiness. Positive psychology adopts a strengths-based perspective (i.e. factors which contribute to things going right, such as 'mental health' as opposed to 'mental illness') in understanding and enhancing wellbeing. Extending the salutogenic perspective, Strümpher, ${ }^{[8]}$ a pioneer in the field of psychofortology, theorised that fortitude resulted in psychological coping, emotional stability and stress tolerance. Following Strümpher's theory, Pretorius ${ }^{[0]}$ expanded on the concept of fortitude within the SA context. He hypothesised that there are three main constructs that contribute to fortitude. They are an evaluative awareness of the self (self-appraisal), an evaluative awareness of family (family appraisal) and an evaluative awareness of social support (support appraisal). Pretorius proposed that fortitude was derived and shaped from the construction of self and world and that these constructions were shaped from our appraisal of ourselves and our perceived sense of family and social support. ${ }^{[9]} \mathrm{He}$ further described that a person with low fortitude would be more prone to self-doubt, impaired perception of personal competency in coping with stressors and a disengagement from active coping efforts. However, a person with high fortitude would be more confident and would adopt more problem-focused styles of coping.

There is limited research in the field of fortitude focusing on medical students. A previous study, which researched salutogenic factors among SA community-service doctors, recommended that it would be beneficial to investigate fortitude, as opposed to salutogenic factors, as fortitude is more holistic and all-encompassing. ${ }^{[10]}$ Equipping students to recognise their inner strengths and resources may assist them in coping with stress and adversity and could result in empowered, confident and well-adjusted individuals. The objective of this article is to explore the relationships between the three 
constructs of fortitude, ${ }^{[9]}$ academic performance and demographic factors in a diverse group of 1st-year medical students.

\section{Methods}

Ethical clearance and gatekeeper approval were obtained from the Human and Social Sciences Ethics Committee at the University of KwaZuluNatal (UKZN), Durban, SA (HSS/0119/013D). A quantitative correlational research design was adopted using convenience sampling. The study was conducted at the Nelson R Mandela School of Medicine at UKZN. All 1st-year medical students in the 2013 cohort were invited to complete the questionnaire adopted for use in the study. A total of 200 questionnaires were distributed, and 165 students consented to participate.

Students' end-of-semester academic results from two academic modules, Becoming a Professional (36-credit bearing) and Basic Science (96-credit bearing), were obtained from the Faculty of Medicine. These are the only two academic modules that all 1st-year students participate in - the other three modules (8-credit bearing), English, isiZulu and Computer Skills, are based on an entrance examination.

\section{Instrument}

The research instrument consisted of 34 questions, to which the students responded using either a nominal or an ordinal scale. The questionnaire was divided into a demographic and fortitude component. Demographic data were collected on gender, race, age, type of school (urban v. rural), sources of funding, and attendance at peer-mentoring and study skills sessions.

The Fortitude Questionnaire (FORQ) was used to assess the fortitude component, adopted from Pretorius and Heyns ${ }^{[11]}$ with permission from the authors. It comprises 20 items aimed at measuring the theoretical construct of fortitude. It has three subscales described below:

- The self-appraisal scale comprises seven items related to the global appraisal of the self, as well as more specific appraisals such as problemsolving efficacy and mastery or competence (e.g. 'I take a positive attitude towards myself').

- The family-appraisal scale has seven items regarding the evaluative awareness of the family environment, such as support from family, level of conflict, cohesiveness in the family and family values (e.g. 'there is plenty of attention for everyone in my family').
- The support-appraisal scale is an evaluative awareness of the support from others. These six items also included beliefs about the efficacy of using such support resources (e.g. 'I am very satisfied with the comfort and support I get from others').

\section{Data analysis}

The data were analysed using Stata/IC 13.0 (StataCorp LP, USA). ${ }^{[12]}$ Descriptive analyses involved computation of summary statistics using frequencies and graphs, based on survey responses. Continuous data were tested for normality using the one-sample KolmogorovSmirnov test. The results of this test revealed that the $p$-values were statistically significant $(p=0.000)$, implying that distribution of the data was not normal. Hence, for inferential statistical analyses, the non-parametric MannWhitney $U$-test was used to test whether the medians of the continuous variables between two independent groups were statistically different at $p<0.05$, and the Kruskal-Wallis test was employed to test the statistical significance of the differences between three or more groups. Where possible, box plots were constructed to show the difference in medians and interquartile ranges of continuous variables across groups. Pearson correlation coefficients were calculated to assess the relationship between academic performance on the two subjects and fortitude subscales, as well as the fortitude composite score. Reliability of the instrument was assessed using Cronbach's $\alpha$.

\section{Results}

The sample was predominantly female (62\%). According to racial background, the sample consisted of black (77\%), Indian (13\%), white (4\%) and coloured (7\%) students. Ages ranged between 18 and 21 years (78\%). Seventy-five percent of participants had attended a state/government school (i.e. poorly resourced), $7 \%$ had attended a private school and $18 \%$ had attended an ex-Model C school (i.e. well resourced). Forty-five percent of participants completed their schooling in a rural area. The majority lived in a university residence (61\%), $29 \%$ lived with family or friends and $10 \%$ lived in a private residence. Twenty-two percent of the students had attended some form of study skills session and $82 \%$ had attended peer-mentoring sessions.

Cronbach's $\alpha$ coefficients were 0.77 for selfappraisal, 0.88 for family-appraisal and 0.82 for support-appraisal scales. This shows a high internal consistency of the items for all three constructs.

A comparison of the medians of the fortitude subscales showed that self-appraisal (20.79), with a range of $8-28$, had the highest median, while support appraisal (16.73), with a range of $2-24$, had the lowest (Table 1). The overall median

Table 1. Descriptive statistics for fortitude and its subscales

\begin{tabular}{llllll}
\hline Scale & $\begin{array}{l}\text { Median } \\
(\text { SD })\end{array}$ & $\begin{array}{l}\text { Items per } \\
\text { subscale, } \boldsymbol{n}\end{array}$ & $\begin{array}{l}\text { Minimum } \\
\text { scored }\end{array}$ & $\begin{array}{l}\text { Maximum } \\
\text { scored }\end{array}$ & $\begin{array}{l}\text { IEP } \\
(\mathbf{a}-\mathbf{b})\end{array}$ \\
\hline Self-appraisal & $20.79(4.23)$ & 7 & 8 & 28 & $(8.20)$ \\
Family appraisal & $19.50(6.50)$ & 7 & 0 & 28 & $(0.28)$ \\
Support appraisal & $16.73(4.26)$ & 6 & 2 & 24 & $(2.24)$ \\
Fortitude & $57.01(11.44)$ & 20 & 20 & 80 & $(20.80)$
\end{tabular}

$\mathrm{SD}=$ standard deviation; $\mathrm{IEP}=$ interval endpoints for each score.

Table 2. Correlations between fortitude and academic performance

\begin{tabular}{|c|c|c|c|c|c|c|c|c|}
\hline \multirow[b]{2}{*}{ Module completed } & \multicolumn{2}{|c|}{$\begin{array}{l}\text { Self-appraisal } \\
\text { score }\end{array}$} & \multicolumn{2}{|c|}{$\begin{array}{l}\text { Family- } \\
\text { appraisal score }\end{array}$} & \multicolumn{2}{|c|}{$\begin{array}{l}\text { Support- } \\
\text { appraisal score } \\
\end{array}$} & \multicolumn{2}{|c|}{$\begin{array}{l}\text { Fortitude } \\
\text { composite score }\end{array}$} \\
\hline & $n$ & $r^{*}$ & $n$ & $r^{*}$ & $n$ & $r^{*}$ & $n$ & $r^{*}$ \\
\hline Becoming a Professional & 158 & $0.23^{\dagger}$ & 158 & $0.20^{\ddagger}$ & 158 & $0.25^{\dagger}$ & 158 & $0.28^{\varsigma}$ \\
\hline Basic Science & 152 & 0.09 & 152 & $0.17^{\ddagger}$ & 152 & $0.22^{\dagger}$ & 152 & $0.20 \ddagger$ \\
\hline $\begin{array}{l}\text { Average of the two assessment } \\
\text { scores }\end{array}$ & 135 & $0.16^{\ddagger}$ & 135 & $0.21^{\varsigma}$ & 135 & $0.29^{\S}$ & 135 & $0.29^{\S}$ \\
\hline $\begin{array}{l}{ }^{*} \text { Pearson's product moment correlation co } \\
{ }^{+} \text {Correlation at } p<0.01 \text { (two-tailed). } \\
{ }^{*} \text { Correlation at } p<0.05 \text { (two-tailed). } \\
{ }^{\circ} \text { Correlation at } p<0.001 \text { (two-tailed). }\end{array}$ & ficient. & & & & & & & \\
\hline
\end{tabular}


for the composite score of fortitude was 57.01 (Table 1).

Fig. 1 shows the distribution of fortitude scores across the 20 different measures posited in the study questionnaire. As illustrated, the majority of the students felt strongly that these statements applied to them. This implies that, with regard to the family-appraisal subscale, students believed that they had strong levels of family support; the self-appraisal subscale revealed that they felt positive about themselves, and the support-appraisal subscale indicated that they were satisfied with the support they received from others. No statistical differences were found between the race groups for all three subscales and the overall fortitude scores.

Median scores for the family-appraisal subscale, the support-appraisal subscale and the fortitude composite score were not statistically different between male and female students ( $p>0.05$; Fig. 2). However, male students had a significantly higher median score than their female counterparts on the self-appraisal subscale $(p<0.0001)$.

The Kruskal-Wallis test revealed statistically significant differences in the composite fortitude scores of students who had attended different types of schools $(p<0.05)$. Those students who had attended state/government schools had the lowest composite median score (Fig. 3).

Fig. 4 illustrates that students with other higher educational experience, such as the completion of another degree, prior to doing medicine, had significantly higher median scores across all three fortitude subscales compared with those without such experience. These differences were statistically significant $(p<0.05$ for the family-appraisal, supportappraisal and self-appraisal subscales; $p<0.001$ for the fortitude composite score).

The results shown in Table 2 indicate that there was a weak but statistically significant correlation between the self, family and support subscales and performance in the Becoming a Professional and Basic Science academic modules. When the three subscales were combined, the resultant fortitude composite score was significantly but moderately correlated with the academic scores of the Becoming a Professional module. Furthermore, the composite score of fortitude was also significantly moderately correlated with the average score for both academic modules.

\section{Discussion}

Three main constructs that contribute to fortitude are the evaluative awareness of the self

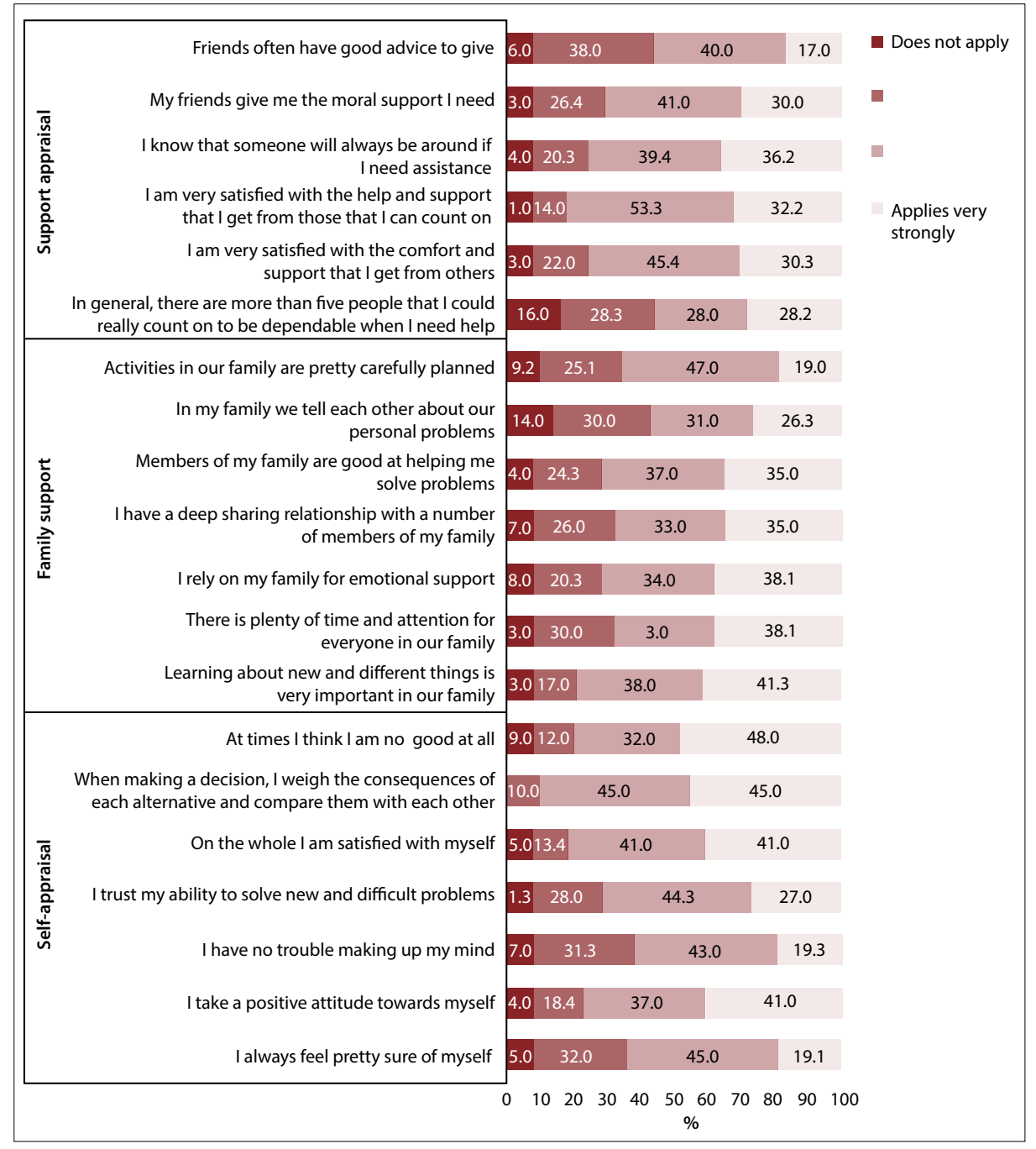

Fig. 1. The distribution of fortitude scores across the 20 different measures of fortitude: analysis disaggregated by fortitude subscale.

(self-appraisal), an evaluative awareness of family (family appraisal) and an evaluative awareness of social support (support appraisal). ${ }^{[1]}$ High internal consistency of the items in all three constructs supports the reliability of the instrument used in this study. We found that the majority of the participants had high levels of fortitude in all three constructs. This implies that this cohort of medical students had positive perceptions or appraisals of themselves, their families and their social supports. The self-appraisal scale presented with the highest mean scores overall for this group of students. This may be due to the finding that, compared with other university students, medical students were known to be highly motivated students. ${ }^{[13]}$ Also, being selected from a massive pool of applicants, these students are constantly reminded that they are the 'cream of the crop'.
Women generally present with greater psychological distress ${ }^{[14]}$ and hence may have lower fortitude scores, as we have found in this study. When comparing mean scores, males had higher fortitude and significantly different scores for self-appraisal than females. Although Rahim ${ }^{[15]}$ did not find any significant relationship between fortitude and gender, Roothman et al. ${ }^{[16]}$ found that men presented with higher fortitude levels than females. The finding in this study reflects that male students have a higher sense of self, i.e. they are more certain of themselves, have more positive attitudes about themselves, have less trouble making up their minds and trust their abilities to solve problems. Dhaniram ${ }^{[10}$ also found, in her research of stress levels among SA community-service doctors, that female students and female physicians showed higher stress levels. These findings highlight the need 


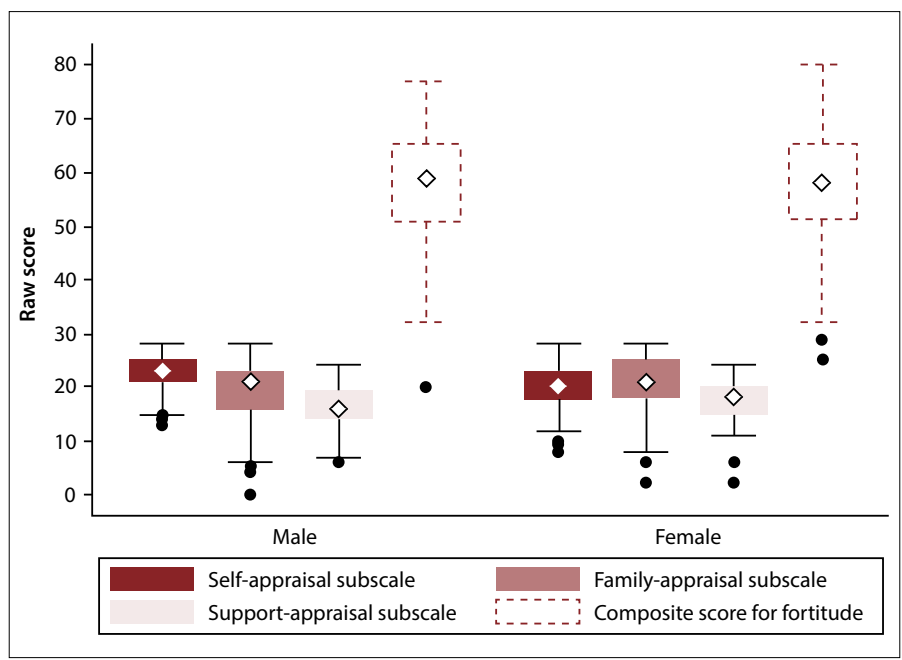

Fig. 2. Distribution of the three fortitude subscale scores by gender.

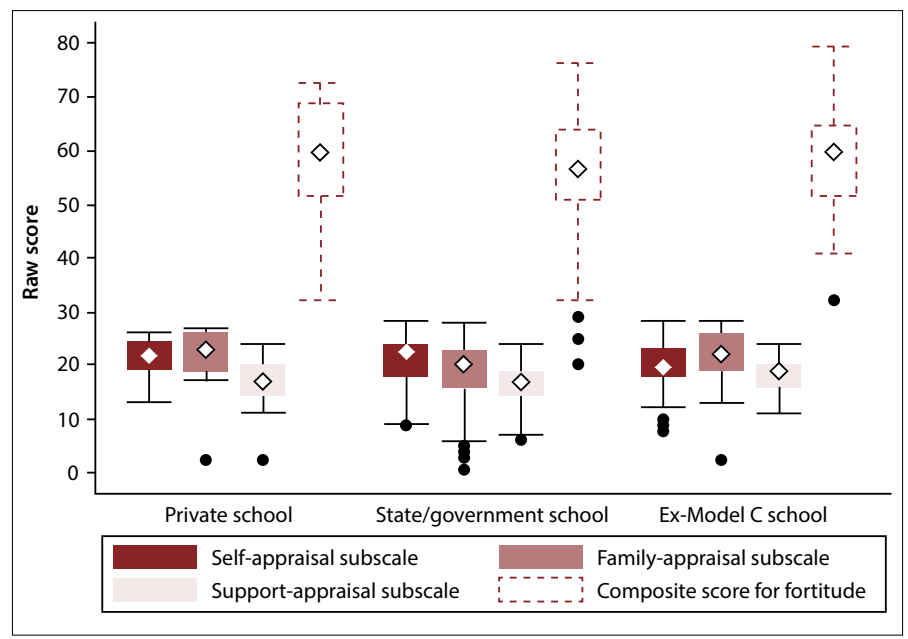

Fig. 3. Distribution of the three fortitude subscale scores by type of school where student matriculated.

for wellbeing programmes that target females, although not to the exclusion of male students. The underlying reasons for this finding should also be explored further using interviews or focus groups.

Students who had acquired other educational experiences or degrees prior to studying medicine had significantly higher median scores across all three fortitude subscales compared with those who had not. These findings may be attributed to the increased experience and level of maturity of these students, compared with those pursuing their first degree directly after high school. ${ }^{[10]}$ Students who had attended state/government schools had significantly lower fortitude than those who had attended private or ex-Model C schools. The type of school attended has been found to influence academic scores. ${ }^{[17]}$ These findings may be attributed to the fact that private and ex-Model C schools have greater infrastructure, resources and much lower teacher-to-student ratios than state schools. They also highlight the need for support programmes to bridge this gap in higher education.

This study contributes to the body of knowledge regarding the association between non-cognitive predictors, such as student psychological wellness on academic performance. ${ }^{[18-20]} \mathrm{A}$ moderately statistically significant

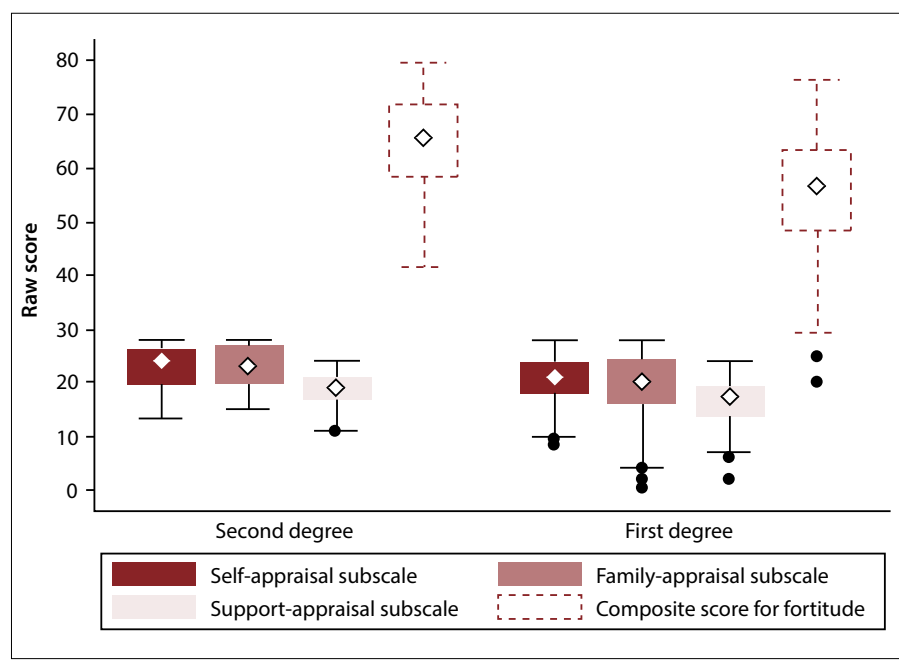

Fig. 4. Distribution of the three fortitude subscale scores by whether student acquired a previous degree.

relationship was found between fortitude and academic performance. This finding highlights the need to investigate confounding variables that may influence academic performance. Hence, further research in this area, preferably with a larger sample, is needed. Furthermore, the weak but statistically significant findings of this study suggest an association between psychological wellbeing and academic performance. ${ }^{[13]}$ Developing fortitude in medical students and fostering an environment of positive social and academic support could have positive implications for academic success. These findings support the need for further exploration of self-development and wellness programmes at medical schools. Such programmes could serve as buffers against medical school stressors and could contribute to enhancing and sustaining fortitude. As the study was limited to 1st-year students only, sampling across all years of medical study is recommended for future studies to investigate the effect of year of study on fortitude. It is also recommended that longitudinal studies be used to assess the fortitude of students as they progress through their years of study. Further validation of the instrument is recommended in other health science settings.

This study was dependent on self-reported information and perceptions from the participant. However, the fortitude instrument used was found to be reliable. It is suggested that further study includes other health science students, such as those from nursing and pharmacy, to gain a more extensive view of the levels of fortitude. This would enable comparison of curriculum and academic environment influences in health science education.

\section{Conclusion}

Male students had significantly higher fortitude scores than females. Students who had attended state/government schools had significantly lower fortitude than those who had attended private or ex-Model C schools. Students with prior degrees had higher fortitude than matriculants. Low and fair levels of fortitude are indicative of a need for corrective measures. These could include consulting the relevant support networks, such as student counsellors, mentors and academic development personnel. The significant, albeit moderate, correlation between fortitude and academic performance highlights the need for further investigation of the fortitude instrument. 
Acknowledgements. This publication was made possible by grant No. R24TW008863 from the Office of the US Global AIDS Coordinator and the US Department of Health and Human Services, National Institutes of Health. Its contents are solely the responsibility of the authors and do not necessarily represent the official views of the US government. The medical students are acknowledged for their participation, and Dr M Muzigaba for statistical guidance and analysis.

\section{References}

1. Nel BP. Academic advising as intervention for enhancing the academic success of 'at-risk students' at a comprehensive university in South Africa. Mediterr J Soc Sci 2014;5(27):732-739. [http://dx.doi.org/10.5901/ mjss.2014.v5n27p732]

2. Pillay AL, Ngcobo HSB. Sources of stress and support among rural-based first-year university students: An exploratory study. S Afr J Psychol 2010;40(3):234-240. [http://dx.doi.org/10.1177/008124631004000302]

3. Ahammed S, Abdullah AS, Hassane SH. The role of emotional intelligence in the academic success of United Arab Emirates university students. Int Educ 2011;41(1):7-21.

4. Brown-Baatjies $\mathrm{O}$, Fouché $\mathrm{P}$, Watson $\mathrm{M}$, Povey JL. The biopsychosocial coping and adjustment of female medical professionals. S Afr J Psychol 2006;36(1):126-143. [http://dx.doi.org/10.1177/008124630603600108]

5. O'Rourke M, Hammond S, O'Flynn S, Boylan G. The medical student stress profile: A tool for stress audit in medical training. Med Educ 2010;44(10):1027-1037. [http://dx.doi.org/10.1111/j.1365-2923.2010.03734]

6. Greysen SR, Dovlo D, Olapade-Olaopa EO, Jacobs M, Sewankambo N, Mullan F. Medical education in sub6. Greysen SR, Dovlo D, Olapade-Olaopa EO, Jacobs M, Sewankambo N, Mullan F. Medical education in sub-
Saharan Africa: A literature review. Med Educ 2011;45(10):973-986. [http://dx.doi.org/10.1111/j.13652923.2011.04039.x]

7. Kelly-Laubscher RF, van der Merwe M. An intervention to improve academic literacies in a first year university 7. Kelly-Laubscher RF, van der Merwe M. An intervention to improve academic literacies in a first y
biology course. Crit Stud Teach Learn 2014;2(2):1-23. [http://dx.doi.org/10.14426/cristal.v2i2.23]
8. Strümpher DJW. The origins of health and stress. From 'salutogenesis' to 'fortigenesis'. S Afr J Psycho 1995;25(2):81-89. [http://dx.doi.org/10.1177/008124639502500203]

9. Loots T, Ebersohn L, Ferreira R, Eloff I. Teachers addressing HIV and AIDS-related challenges resourcefully. Southern Afr Rev Educ 2012;18(1):56-84

10. Dhaniram N. Stress, burnout and salutogenic functioning amongst community service doctors in KwaZuluNatal. MA thesis. Pretoria: University of South Africa, 2003. http://hdl.handle.net/10500/1526 (accessed 19 Apr 2016).

11. Pretorius TB, Heyns PM. Fortitude as stress-resistance: Development and validation of the Fortitude Questionnaire (FORQ). 2005. http://citeseerx.ist.psu.edu/viewdoc/download?doi=10.1.1.464.1299\&rep=rep1\& type=pdf (accessed 15 June 2012).

12. StataCorp. Stata Statistical Software: Release 13. College Station, TX: StataCorp LP, 2013.

13. Jafari N, Loghmani A, Montazeri A. Mental health of medical students in different levels of training. Int J Prev Med 2012;3(Suppl 1):s107-s112.

14. Akhlaq BA, Arouj K. Study on the self-esteem and strength of motivation of medical students. Int J Bus Humanit Technol 2014;4(5):58-63.

15. Rahim MZ. Investigating the relationship between fortitude and academic achievement in students from historically disadvantaged backgrounds. MPsych thesis. Cape Town: University of the Western Cape, 2007. http:// hdl.handle.net/11394/2762 (accessed 19 April 2016).

16. Roothman B, Kirsten DK, Wissing MP. Gender differences in psychological well-being. S Afr J Psychol 2003;33(4):212-218

17. Sommerville T, Singaram VS. The whole is greater than the sum: A longitudinal study of demographic influences on medical student assessment scores. Alternation 2015;17:28-53.

18. Singaram VS, van der Vleuten CP, Muijtens AM, Dolmans DH. Relationships between language background, secondary school scores, tutorial group processes and students' academic achievement in PBL: Testing a causal model. Interdiscip J Probl Based Learn 2012;6(1):153-164. [http://dx.doi.org/10.7771/1541-5015.1316]

19. Sommer M, Dumont K. Psychosocial factors predicting academic performance of students at a historically disadvantaged university. S Afr J Psychol 2011;41(3):386-395. [http://dx.doi.org/10.1177/008124631104100312]

20. Van Lingen JM, Douman DL, Wannenburg I. A cross-sectional exploration of the relationship between undergraduate nursing student wellness and academic outcomes at a South African higher education institution
und S Afr J Psychol 2011;41(3):396-408. [http://dx.doi.org/10.1177/008124631104100313] 